\title{
On a mission: Achieving distinction as a business school?
}

\author{
D.L. Bevelander ${ }^{\mathrm{a}}$, M.J. Page ${ }^{\mathrm{b} *}$, L.F. Pitt ${ }^{\mathrm{c}}$ and M. Parent ${ }^{\mathrm{c}}$ \\ ${ }^{a}$ Rotterdam School of Management, Erasmus University, Burgemeester Oudlaan 50, J-building, 3062 PA Rotterdam, The Netherlands \\ ${ }^{\mathrm{b}}$ Bentley University, 175 Forest Street, Waltham, Massachusetts, 02452, USA \\ ${ }^{\mathrm{c}}$ Segal Graduate School, Beedie School of Business, Simon Fraser University, 500 Granville Street, Vancouver, BC V6C-1W6, Canada \\ *To whom all correspondence should be addressed \\ mpage@bentley.edu
}

\begin{abstract}
This paper investigates what business schools are saying in their mission statements and whether they provide a meaningful basis for strategic choice, distinction and differentiation from a positioning perspective; or whether they are the equivalent of "table stakes" in the MBA game - undifferentiated signals that connote legitimacy. Content analysis is undertaken of the mission statements of the Financial Times 2009 top 100 full-time MBA program offering business schools. The statements are mapped and compared in the aggregate and by quartile. We conclude that the statements are for the most part homogeneous and do not serve as a basis for differentiation. However, although achieving distinction through a mission statement may indeed be difficult, it is by no means impossible, and we suggest approaches that business school deans might adopt in an effort to make their brands stand out.
\end{abstract}

\section{Introduction}

Mission statements, long accepted as an important part of the strategic planning and implementation process in the corporate world (Keller, 1983; Pearce \& Robinson, 1991), have also increasingly become requirements for tertiary education institutions. Like corporations, they face increasingly levels of competition and are responding by adopting more business-like approaches that undeniably include shifting from traditional and rather broad strategic planning cycles to mission-inspired strategic positioning (Leland \& Moore, 2007: 11).

This corporatization of strategic planning within higher education brings with it the need to critically examine internal institutional strengths and then position them within the context of the external stakeholders the institution seeks to serve. This is not easy for many faculty members who are more inclined to a belief in the importance of their disciplines, and that the external community needs to be educated. A supply-side rather than demand-side philosophy to serving the market requires clearly articulated mission statements that are developed through appropriate stakeholder engagement and that are seen as important vehicles for educating the internal market about strategic choices and decision execution. An illustration of this approach is provided by Koteen (1997: 135), who described Duke University's 1990's creation of a distinctive mission statement that articulated the institution's strategic themes and imperatives, and established its ongoing competitive advantage.

Mission statement prevalence has also been brought about by accrediting bodies increasingly requiring that entities publish clear mission statements and demonstrate that they inform strategic development. As illustration, AACSB
International's strategic management standards require that each school "publishes a mission statement or its equivalent that provides direction for making decisions" ... and ... "periodically review and revise the mission statement as appropriate” (AACSB International, 2010: 16). Similarly, the EFMD, through its European quality improvement system (EQUIS) states that peer reviewers must assess the "appropriateness of the mission statement" and whether there is a "shared sense of mission and vision throughout the school" (European Foundation for Management Development, 2010: 33). The obligation has been further supported by demands of boards of trustees and other external stakeholders.

Beyond supporting strategic choice, mission statements are also seen as important marketing tools. Externally, they signal the organization's professional identity, frame its choice of activities, and facilitate positioning vis-à-vis its competitors (Hartley, 2002; Short \& Palmer, 2008). Internally, they help clarify the philosophy and intent of the organization to its employees and students (Davies \& Glaister, 1997).

This exploratory study investigates what business schools are saying in their mission statements; whether they provide a meaningful basis for strategic choice; and, whether they offer the necessary distinction or differentiation from a positioning perspective. Content analysis of the mission statements of the Financial Times ${ }^{1} 2009$ top 100 international full-time MBA program schools is undertaken.

\footnotetext{
1 The Financial Times undertakes annual ranking surveys for full-time MBA programs, part-time or executive MBA programs, Master of Science in Business Administration programs, and business schools involved in executive education. These rankings are based upon multiple criteria that span post graduation salaries, perceptions of quality, international character, diversity, and research.
} 
The dataset is also divided into quartiles to establish whether mission statement content differs across ranking clusters.

The paper begins with an overview of mission statements and discusses their relevance for universities and business schools. Pertinent literature is reviewed. Thereafter, the methodology and the specific content analysis software utilized, Leximancer ${ }^{\mathrm{TM}}$, are outlined. Third, results are presented followed by analysis and discussion. The article concludes with a fifth section that interprets the findings and the implications for business schools, acknowledges the limitations of the research, and identifies avenues for future research.

\section{Mission statements: Their nature and purpose}

The academic and professional strategic management literature has devoted considerable attention to the importance of mission statements as professional communications. More than fifty years ago, Jones (1960) emphasized the importance of business philosophy and the effect that mission statements have on organizational goals, decision-making, and community responsibility. Extant literature provides numerous interpretations of what mission statements are, and views about their purpose and real value. While some scholars have been somewhat cynical about the effectiveness of mission statements, and the sincerity of executives in formulating them (e.g. Bartkus, Glassman and McAfee, 2000), others (e.g. Verma, 2009) have argued that vision and mission statements are powerful strategic communications tools that get organizations to coalesce around central themes.

Empirical research into the efficacy of mission statements has produced mixed results (Sidhu, 2003). Some researchers have suggested mission statements do not always have the desired impact (Barber 2005; Meyer, 2005) while others have been even more cynical and concluded that they are often a collection of stock phrases that are either excessively vague or unrealistically inspirational or both (Morphew \& Hartley, 2006: 457; see also Bartkus et al., 2000). Davies and Glaister (1997) found little evidence of a relationship between the performance of a company and its mission statement and argued, paradoxically, that mission statements seem to be created when organizations are directionless or there is a change in top management. Bartkus and Glassman (2008) established that organizations mentioning particular stakeholder groups in their mission statements display little in the way of behaviors that are consistent with this.

In contrast to the above, some research finds mission statements can have a positive impact on broad aspects of organizational performance. Klemm, Sanderson, and Luffman (1991) concluded that a mission statement, which includes a statement of company values, is an important communications tool for managers to assert their leadership within the organization. Baetz and Bart (1996) found that most large firms had a mission statement, that the top management group was most involved in its creation, that it was used for a variety of purposes, and that the majority of firms were satisfied with the statement and the process they had used to create it. Later work by the same authors (Bart and Baetz, 1998) led them to conclude that key aspects of mission statements are associated with higher levels of organizational performance.

\section{Mission statements in higher education}

The limited amount of tertiary education sector mission statement research has tended to find that the statements are bland, generalist, and apparently designed to ensure flexibility and to signal their "university-ness" (Chait, 1979; Davies, 1986; Delucchi, 1997; Morphew \& Hartley, 2006; Lowrie, 2007). Chait's (1979) deconstruction of college mission statements found their vagueness made them all essentially the same. He concluded that statements such as the pursuit of excellence or the discovery and transmission of knowledge were vague enough to make it impossible to demonstrate whether or not the institutions were achieving or falling short of their strategic aspirations (Chait, 1979: 36). Hemsley-Brown and Goonawardana (2007) concurred, but did not see this as necessarily a disadvantage, concluding that brand harmonization, albeit in a very broad way, was evolving in the industry. Research has also found that the typically broad nature of university mission statements means they do not provide necessary direction, that they are seldom referred to or reflected upon, and that they are generally incapable of directing strategic choice (Davies and Glaister, 1997; Morphew \& Hartley, 2006). Furthermore, Morphew and Taylor (2009) have found that many higher-education institutions use more than one mission statement - one on their Web page and another for the Web site of U.S. News \& World Report. They argue that while multiple versions may not be a problem if mission does not really matter, if it does matter, then having a number of different versions (brand disharmony) detracts from their real purpose, calls into question the intention of the leadership, and can be interpreted as merely a superficial marketing tool.

Meacham (2008) is less skeptical of mission statements within higher education. He argues that mission statement creation importantly engages key internal stakeholders including both faculty and administrators - in a dialogue about purpose and longer-term direction for the institution. Somewhat optimistically, he states that "(mission statements) can help get folks on your campus talking to each other, for one thing" (Meacham, 2008: 21). This observation is consistent with Krohe's (1995) finding that the primary benefit of mission statements is in their creation.

Surprisingly, given the espoused importance of stakeholder engagement within the higher education sector, it appears students have little influence in developing business school mission statements. Davies and Glaister's (1997) survey of United Kingdom business schools, found that school leadership and senior professors had the most influence, followed by other academic staff and university leadership, with student representatives playing only a minor role at best (Davies \& Glaister, 1997: 567). 


\section{Purpose of mission statements}

In spite of continued debate about the efficacy of mission statements within both the corporate and education sectors, the perceived importance of mission statements is generally accepted to include that they give purpose and vision for the future. Further arguments for the importance of mission statements include strategic direction setting (Keller, 1983; Martin, 1985; Pearce \& Robinson, 1991; Nanus, 1992), internal and external marketing and communications (Keller, 1983; Davies \& Glaister, 1997; Hooley, Cox \& Adams, 1992; Hartley, 2002), and establishing distinctiveness (Drucker, 1973; Wheelan \& Hunger, 1989; Davies \& Glaister, 1997).

\section{Researching mission statements using content analysis}

A number of studies have used content analysis to study mission statements of multiple organizations. Pearce and David's (1987) content analysis of Fortune 500 firm mission statements found that higher financial performer mission statements differed from lower performers. Specifically, higher performers gave special attention to their corporate philosophy and to the organizations basic beliefs, values, aspirations, and priorities; self-concept, including competitive strengths; and, desired public image. David's (1989) subsequent study of seventy-five large company mission statements revealed nine key components. Amato and Amato (2002) content analyzed corporate mission statements to investigate the relationships between commitment to quality of life and firm size, profitability, and industry. Lee, Fairhurst and Wesley's (2009) web page analysis of the top one-hundred United States retail organizations explored their corporate social responsibility policies and actions.

Studies of university and business school mission statements have also employed content analysis techniques. Short and Palmer (2008) explored relations between mission statement content and measures of business school characteristics, including performance, for 408 AACSB International member business schools. They found considerable variance across school missions but argued that the statements generally lacked comprehensiveness. Buff and Yonkers (2004) content analyzed the mission statements and curriculum requirements of 286 AACSB International schools with undergraduate marketing programs and found that $64 \%$ either had mission statements that included ethical content; had ethics course requirements; or both.

In this study, we further investigate whether mission statements represent clear positioning statements that help distinguish one institution from another, as suggested by Hemsley-Brown and Goonawardana, (2007) and Short and Palmer (2008), or are strikingly consistent communications that serve to signal consistency and belonging to the broader academic community (Lowrie, 2007).

\section{Methodology}

The study uses data extracted from the internationally recognized top 100 business schools identified through the Financial Times ${ }^{\mathrm{TM}}$ (2009) full-time MBA ranking study. The selection was further motivated by the fact that all of these schools are accredited by at least one of the international accrediting bodies.

The first phase of the methodology involved extracting as many mission statements from the business schools' websites as possible. Where keyword searches of the business school website did not reveal a unique school mission, vision or purpose, but pointed to the parent university statement and/or to specific divisional statements within the school, it was assumed that a school-specific mission statement did not exist and the parent institution mission was adopted if it was available. Nine schools were contacted directly to either provide their mission statement or confirm that it did not exist.

The analysis methodology employed a five-step procedure:

- Each mission statement was scanned to remove specific identifying words including the name of the business school or of its parent entity. These were changed to merely state the School and the University respectively and capitalized to identify them as nouns rather than general identifiers of organization type where the lowercase form was employed. In a similar fashion, schools that identified their own city or country by name had these changed to the capitalized form of the City and the Country. This was done to correctly identify the nouns as self-referencing rather than case specific and therefore unimportant for concept identification.

- Each statement was consolidated into the most common general framework used by the schools to ensure the content analysis software dealt with the mission statements in a consistent fashion and then appended to two of five .html files. One file for all 100 mission statements and four separate files for each quartile.

- The five .html files were then analyzed using Leximancer ${ }^{\mathrm{TM}}$ and following a two step procedure. An initial pass through of the data resulted in initial identification and ranking of concepts using both name and word based concepts. Name being defined by the package as a word within the body of a sentence that begins with a capital letter - "school" is a word while "School" is a name. The second step involved the removal of the two names "School" and "University" and the word "mission" if they were found to be present in the identified concepts, and, where necessary, extending the number of included concepts to the point where the first excluded concept occurred less than ten percent of the time of the most identified concept. Extracted output from the second phase analysis of each dataset included the ranked sequence of identified 
concepts with their frequency of occurrence and a color map of the identified concepts showing their relative importance and degree of connectedness.

- The fourth step of the methodology was designed to overcome two potential difficulties with interpreting the content analysis outcome. Each of the data files contained multi-sources and authored text opening the possibility that the software might identify what is in reality a single concept as multiple concepts because of different terms and word usage. As illustration, words and clusters of words around global, worldwide, and international may all relate to the concept international. The second potential difficulty is that the same concept may occur multiple times within one mission statement but be absent from others. Concept frequency may therefore not be consistent with the number of the business schools identifying the concept in their mission. Assessing the impact of these two potential difficulties involved extracting the full set of software identified concept words and:

- Searching for the occurrence of each of the concept words in each mission statement using a binary indicator to indicate its presence or absence.

- Grouping the concept words into appropriate clusters of synonyms using the Microsoft Word ${ }^{\text {TM }}$ thesaurus and confirming that the synonyms were used with the same intent across the schools using them. As illustration, "knowledge" was coidentified with "research" when analysis of a mission statement confirmed that the word was used in connection with the scholarly endeavors of the faculty. Each cluster was then assigned a macro concept name.

- Each mission statement was then flagged as either including or not-including each of the identified macro concepts.

- As a final step, the numbers of mission statements that included each macro concept were counted to assess if the proportional use of these concepts varied across the quartiles using the Marascuilo (1966) comparison of multiple proportions test.

\section{Leximancer ${ }^{\mathrm{TM}}$ content analysis software package}

LeximancerTM is a relatively simple but powerful software program designed for visualizing and interpreting complex textual communication ${ }^{2}$. It uses data-mining techniques to interpret prose and identify the main concepts in a corpus of text, as well as how these concepts relate using conceptual (thematic) and relational (semantic) analyses (Rooney, 2005). The text is then displayed visually by means of a concept map that portrays the main concepts and their interrelationships. Concepts are conceived of as collections of words that travel together, and concept maps show the overall representation of the corpus, and guide in its interpretation. They present the relative importance of concepts and strength of interaction graphically through size, color ${ }^{3}$ and location - large circles represent key themes and dots individual concepts, color-coding reveals the relative importance of the themes and concepts, and related concepts that are strongly semantically linked are drawn close to one another (Rooney, 2005: 410-412).

The Leximancer ${ }^{\mathrm{TM}}$ algorithm is based on Bayesian theory where the degree of belief in a relationship or hypothesis changes as evidence is gathered iteratively by the package. The software has been validated in prior research with the automatic selection of key concepts and entities within text demonstrating good agreement with expert human judgments over many trials (Rooney, 2005; Campbell, Pitt, Parent and Berthon, 2011). Scholars have employed Leximancer $^{\mathrm{TM}}$ across a wide range of disciplines in the social sciences (Scott and Smith, 2005; Smith and Humphreys, 2006; Martin and Rice, 2007). The package has been shown to be robust, and to afford a more nuanced and complete view of interrelationships (Campbell et al., 2011).

\section{Results}

The 100 business school mission statements extracted for the study ranged in length from four words for IMD to 262 words for HEC Paris. By length, the $10^{\text {th }}$ percentile, $25^{\text {th }}$ percentile, median, $75^{\text {th }}$ percentile, and $90^{\text {th }}$ percentile contained twelve, twenty-four, thirty-eight, sixty-nine, and ninety-nine words respectively. Illustrating the range of statements are the Washington University in St. Louis' Olin Business School at six words and the University of Melbourne's Melbourne Business School at 139 words. Respectively, these statements are:

\footnotetext{
${ }^{2}$ See www.leximancer.com, accessed August 6, 2010.

${ }^{3}$ The figures presented in the paper use shades of grey rather than colours with darker grey representing brighter colors.
} 
Create knowledge ... inspire individuals ... transform business ${ }^{4}$

and

We are a school of business whose primary function is the creation and transfer of management education and knowledge. We do so with rigor and relevance, and use the best business and management practices that we espouse and teach. Through the synergy of our teaching, research and service we will contribute to the business, cultural, economic, and social well-being of our communities and constituents. We offer holistic educational experiences to our students and participants to better prepare them to assume leadership roles in organizations across the sectors and across the world. We do this with a dedication to a sustainable future through dedication to principles for responsible management education. Global, business, leaders - this, our promise, encapsulates and symbolizes who we are, who we aspire to be, and what we hope to prepare our students and participants to become . $^{5}$

Table 1 presents the concepts identified for the full set of data and for each of the four quartiles. The table lists each concept, the frequency of its occurrence, and its percentage occurrence based upon the number of schools in the sample. This format is slightly different to the output produced by the package but entirely consistent with it. As illustration, the concept "business" is found to appear a total of fifteen times or a sixty percent occurrence in the .html file that contains the mission statements for the twenty-five secondquartile schools. Leximancer ${ }^{\mathrm{TM}}$ reports the percentages (proportions) as a function of the most frequently occurring concept. This results in the most frequently occurring concept for each dataset always being recorded as onehundred percent despite the fact that it may occur in considerably less mission statements. For this study, it is considered more useful for comparative purposes to record the relative frequencies on a standardized basis - the sample size.

Table 1 demonstrates some rather stark differences across the quartiles. Only "business", "leaders" and "students" are identified as common concepts. Surprisingly, the concepts "research" and "knowledge" are not pervasive and occur only once and twice across the four quartiles respectively. Reasons for, and possible implications of, these findings are presented in the discussion and implications section of the paper.

Figures 1 and 2 present the concept maps with the dominance of the separately identified concepts "research", "business", "students", and "leaders" - all of which have large individual location or identification dots attached to them - clearly evident in Figure 1. The concept dots and the

\footnotetext{
${ }^{4}$ http://www.olin.wustl.edu/aboutolin/Mission/Pages/default.aspx, accessed August 6, 2010.

http://www.mbs.unimelb.edu.au/go/about-mbs/mbs-mission-statement, accessed August 6, 2010.
}

attendant circles that aggregate the concepts into co-located themes highlight the importance of these four concepts as dominant overall themes across almost all business schools. Additionally, the clustering evident within and across the themes has both intuitive and less easily understood elements. For instance, having "research" and "knowledge" clustered together under the RESEARCH theme makes intuitive sense, as does "business" and "management" clustered under the BUSINESS theme. However, the identification of "global" and "society" with the RESEARCH theme is less obvious until one appreciates that these global and societal issues are frequently mentioned within the same sentence (context) as research and knowledge. Similarly, "alumni" and "leadership" are associated with segments of mission statements that discuss STUDENTS, while "education" is more frequently associated with BUSINESS within sentences and phrases. Interestingly, the individual concept "leaders" is quite distant from the other concepts and is almost unique as a theme with only one of the minor concepts, "aim", associated with it in forming the theme LEADERS. 
Table 1: Leximancer ${ }^{\mathrm{TM}}$ concept frequencies

\begin{tabular}{|c|c|c|c|c|c|c|c|c|c|c|}
\hline \multirow[b]{2}{*}{ Research } & \multicolumn{2}{|c|}{ All 100 missions } & \multicolumn{2}{|c|}{ Q1 missions } & \multicolumn{2}{|c|}{ Q2 missions } & \multicolumn{2}{|c|}{ Q3 missions } & \multicolumn{2}{|r|}{ Q4 missions } \\
\hline & 104 & $104.0 \%$ & & & 8 & $32.0 \%$ & & & & \\
\hline Business & 76 & $76.0 \%$ & 27 & $108.0 \%$ & 15 & $60.0 \%$ & 28 & $112.0 \%$ & 19 & $76.0 \%$ \\
\hline Knowledge & 64 & $64.0 \%$ & & & 26 & $104.0 \%$ & 28 & $112.0 \%$ & & \\
\hline Leaders & 50 & $50.0 \%$ & 27 & $108.0 \%$ & 12 & $48.0 \%$ & 27 & $108.0 \%$ & 6 & $24.0 \%$ \\
\hline Management & 44 & $44.0 \%$ & & & 9 & $36.0 \%$ & & & 10 & $40.0 \%$ \\
\hline Students & 41 & $41.0 \%$ & 6 & $24.0 \%$ & 11 & $44.0 \%$ & 6 & $24.0 \%$ & 22 & $88.0 \%$ \\
\hline Education & 38 & $38.0 \%$ & & & & & & & & \\
\hline Teaching & 33 & $33.0 \%$ & & & 7 & $28.0 \%$ & & & 10 & $40.0 \%$ \\
\hline Society & 28 & $28.0 \%$ & 9 & $36.0 \%$ & & & & & & \\
\hline Global & 27 & $27.0 \%$ & & & & & & & 10 & $40.0 \%$ \\
\hline World & 26 & $26.0 \%$ & 11 & $44.0 \%$ & 8 & $32.0 \%$ & & & & \\
\hline Community & 22 & $22.0 \%$ & & & 11 & $44.0 \%$ & 3 & $12.0 \%$ & & \\
\hline Create & 22 & $22.0 \%$ & & & & & & & & \\
\hline Leadership & 21 & $21.0 \%$ & & & 9 & $36.0 \%$ & & & & \\
\hline Organizations & 20 & $20.0 \%$ & & & & & & & 6 & $24.0 \%$ \\
\hline Environment & 17 & $17.0 \%$ & & & & & 4 & $16.0 \%$ & 10 & $40.0 \%$ \\
\hline Social & 17 & $17.0 \%$ & & & & & & & 5 & $20.0 \%$ \\
\hline International & 16 & $16.0 \%$ & & & & & & & & \\
\hline Develop & 15 & $15.0 \%$ & & & & & & & & \\
\hline Economic & 13 & $13.0 \%$ & & & & & & & 5 & $20.0 \%$ \\
\hline Service & 13 & $13.0 \%$ & & & 8 & $32.0 \%$ & & & & \\
\hline Alumni & 10 & $10.0 \%$ & & & & & & & & \\
\hline Values & 10 & $10.0 \%$ & & & & & & & & \\
\hline Integrity & 6 & $6.0 \%$ & & & & & & & & \\
\hline Personal & 6 & $6.0 \%$ & & & & & & & & \\
\hline Standards & 6 & $6.0 \%$ & & & & & & & & \\
\hline Aim & 5 & $5.0 \%$ & & & & & & & & \\
\hline Highest & & & 4 & $16.0 \%$ & & & & & & \\
\hline Culture & & & 3 & $12.0 \%$ & & & & & & \\
\hline Training & & & 3 & $12.0 \%$ & & & & & & \\
\hline Managers & & & 3 & $12.0 \%$ & & & & & & \\
\hline Level & & & 3 & $12.0 \%$ & & & & & & \\
\hline Create & & & & & 8 & $32.0 \%$ & & & & \\
\hline Practice & & & & & 5 & $20.0 \%$ & & & & \\
\hline Developing & & & & & 4 & $16.0 \%$ & & & & \\
\hline People & & & & & 4 & $16.0 \%$ & & & & \\
\hline Excellence & & & & & & & 7 & $28.0 \%$ & & \\
\hline Committed & & & & & & & 4 & $16.0 \%$ & & \\
\hline Sustainability & & & & & & & 3 & $12.0 \%$ & & \\
\hline Learning & & & & & & & 3 & $12.0 \%$ & & \\
\hline Academic & & & & & & & 3 & $12.0 \%$ & & \\
\hline Outstanding & & & & & & & & & 4 & $16.0 \%$ \\
\hline Capable & & & & & & & & & 4 & $16.0 \%$ \\
\hline Understanding & & & & & & & & & 3 & $12.0 \%$ \\
\hline
\end{tabular}

The first column of each set provides the numbers of occurrences of the Leximancer ${ }^{\mathrm{TM}}$ identified concepts; the second column provides the relative frequency given the number of included mission statements - 100 for the full dataset and 25 for each quartile of the dataset. 


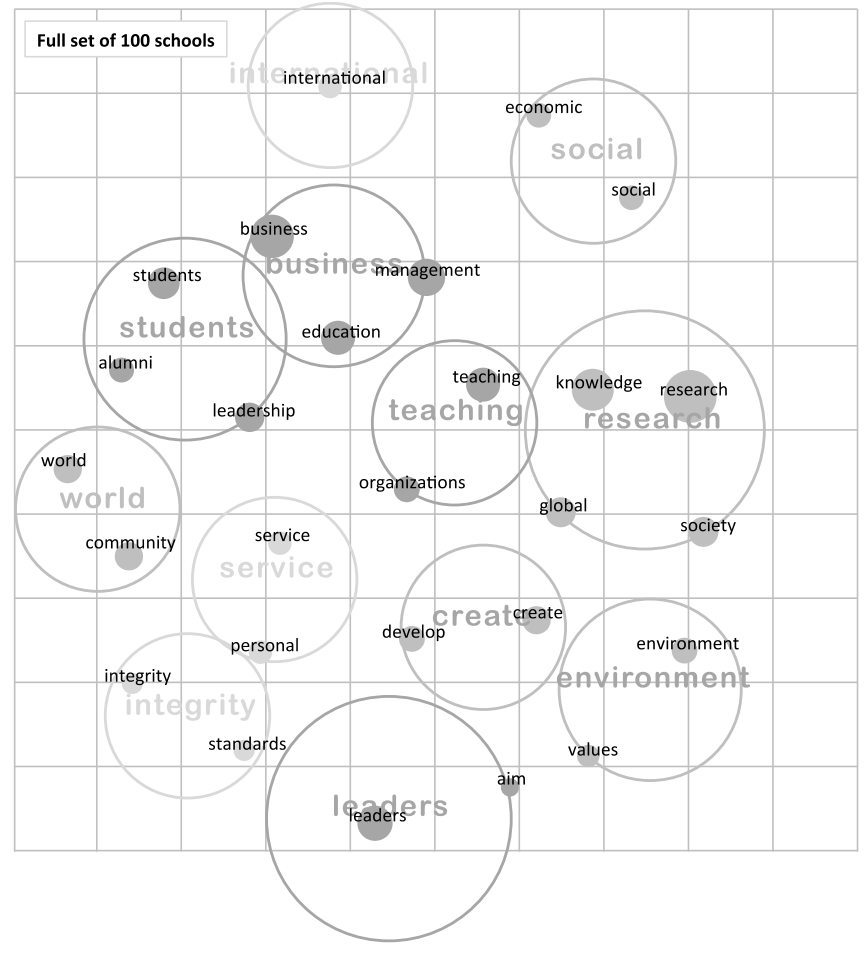

Figure 1: Leximancer ${ }^{\mathrm{TM}}$ maps for the 2009 financial times top 100 Business Schools
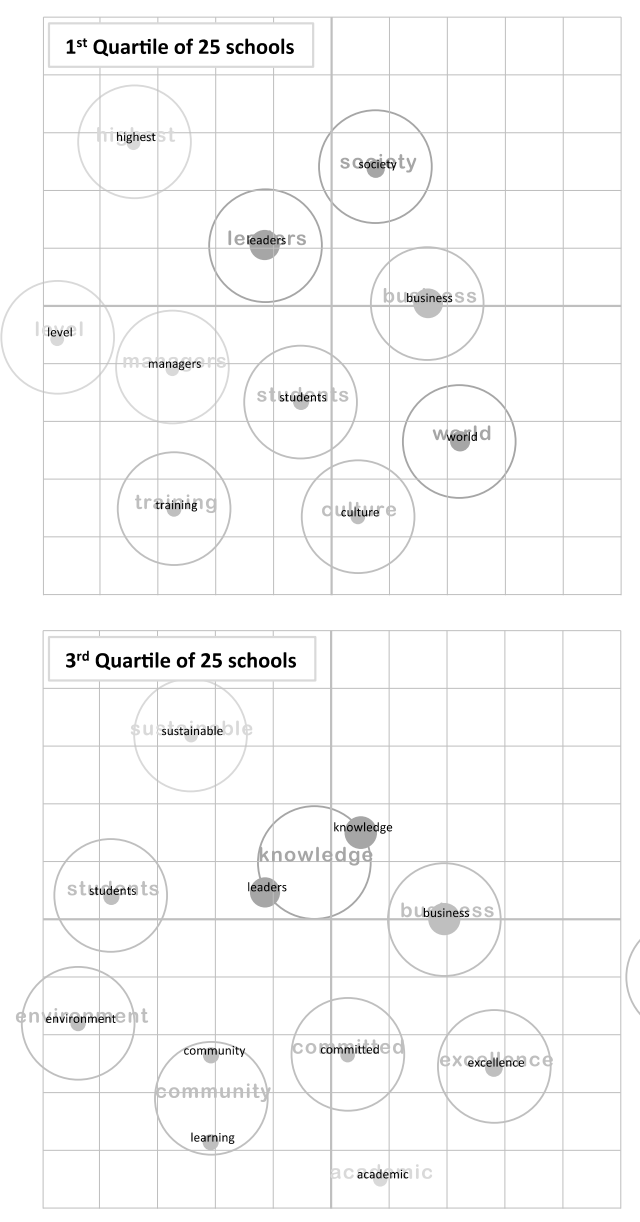

Figure 2 presents the concept maps for the four quartiles juxtaposed against one another. Common characteristics of the maps are that there are slightly fewer themes than for the overall dataset and that the themes tend to be more dispersed or distinctive than in the integrated analysis. Across the four quartiles, twenty-eight of the thirty-nine themes are identified with unique concepts, ten themes are identified with two concepts each, and one theme is associated with three concepts. Dominant concepts across the quartiles include "business", "leaders" and "students" that are mentioned across all four and, to a lesser extent, "knowledge", "management", "world" and "community" that are mentioned across two quartiles each. Interestingly, nine of the concepts identified for the full dataset of one-hundred mission statements do not appear in any of the quartile maps. Somewhat surprisingly, the "research" concept that appeared to be relevantly prevalent in the overall map only appears in the second quartile of mission statements.

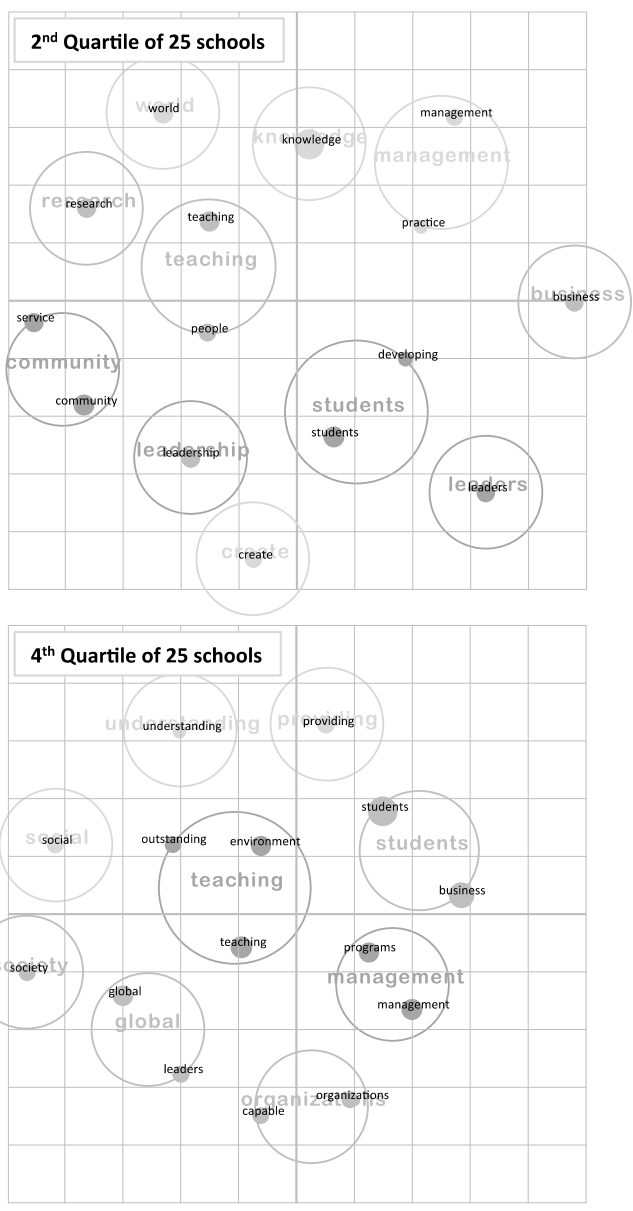

Figure 2: Leximancer ${ }^{\mathrm{TM}}$ maps across four quartiles 
Transforming the mission statements to improve style consistency and to remove specific university and business school names (as described in the first step of the methodology) resulted in the full set of mission statements .html file consisting of 5,120 words and 1,044 unique words. In this context, words are considered unique unless they are perfectly equivalent to another. Of these, Leximancer ${ }^{\mathrm{TM}}$ identified a total of 415 unique concept words and names, forty-four of which the package included in one or more of the concept maps as is evident from Table 1. Examining the key words underlying each of the concepts using the Microsoft Word ${ }^{\mathrm{TM}}$ thesaurus combined with a manual reexamination of the underlying text suggested that the fortyfour selected concept words plus an additional 118 concept words could reasonably be consolidated into the twenty-two aggregated concepts presented in Table 2 .

\section{Table 2: Leximancer ${ }^{\mathrm{TM}}$ concept aggregation}

$\begin{array}{lc}\text { [1] Aim } & \text { [5] Create } \\ \text { aim/s } & \text { accomplish } \\ \text { aspirations } & \text { create/d/ing/ion } \\ \text { creative/ity } \\ \text { aspire } & \text { forward-thinking } \\ \text { inspire/ing } & \text { generate/ing } \\ \text { perspective/s } & \text { ideas } \\ \text { pursue } & \text { produce } \\ \text { pursuit } & \text { transform } \\ \text { seek } & \text { unique } \\ & \\ \text { [2] Alumni } & \text { [6] } \begin{array}{l}\text { Develop } \\ \text { alumni }\end{array} \\ \text { graduate/s } & \text { ability } \\ & \text { achieve } \\ \text { [3] Business } & \text { advance/s/ing } \\ \text { business/es } & \text { advancement } \\ \text { companies } & \text { build/t/ing } \\ \text { corporate } & \text { develop/s/ing } \\ \text { enterprise } & \text { development/a } \\ \text { organization/s/al } & \text { enhance/d/ing } \\ \text { partners } & \text { foster/s/ing } \\ \text { partnerships } & \text { improve } \\ \text { practice } & \text { [7] Economic } \\ & \text { benefit } \\ \text { [4] Committed } & \text { career } \\ \text { believe } & \text { economic/s } \\ \text { committed/ment } & \text { economy } \\ \text { dedicated/ion } & \text { growth } \\ \text { essential } & \text { markets/place } \\ \text { strive } & \text { prosperity } \\ & \text { wealth } \\ & \\ & \end{array}$

[8] Education
academia
academic
educate/s/ing
education/al
learning
teach/ing
training
understanding

[9] Environment environment sustainable

\section{[10] Ethical}

ethical

integrity

standards

\section{[11] Excellence}

excel

excellence/ent

exceptional

high/est/ly

high-quality/level

outstanding
[12] Global
global/ly international/ly world/wide

\author{
[13] Leadership \\ lead/ing \\ leader/s \\ leadership
}

[14] Management

management
managerial
managers

[15] Provide

contribute

offer/ing

provide/ing

[16] Scholarship

analytic/al

intellectual

knowledge

research/ing

research-based

research-led

scholarly/ship

science

scientific

theory

[17] Service

serve/s

service/s

\author{
[18] Society \\ citizens \\ community/ies \\ constituents \\ members \\ network \\ people \\ social \\ society \\ stakeholders
}

[19] Staff

staff

\section{[20] Students}

post-graduate

student/s

undergraduate/s

\section{[21] Transformation \\ lives \\ personal \\ personalized}
[22] Values
culture
principled
values

Figure 3 graphs how many of the 100 mission statements include the twenty-two aggregated concepts as well as the residual concept words that did not form part of the concept maps. The figure clearly demonstrates the broad distribution of the residual concept words across the business schools with most occurring in considerably less than ten percent of the mission statements. The average frequency of occurrence across schools is three-and-a-half times, and the concept words that appear in more than ten percent of the mission statements are "principled", "disseminate", "faculty", "professionalism", "programs", and "thought" all words that could have been included in the aggregated concepts listed in Table 2. 


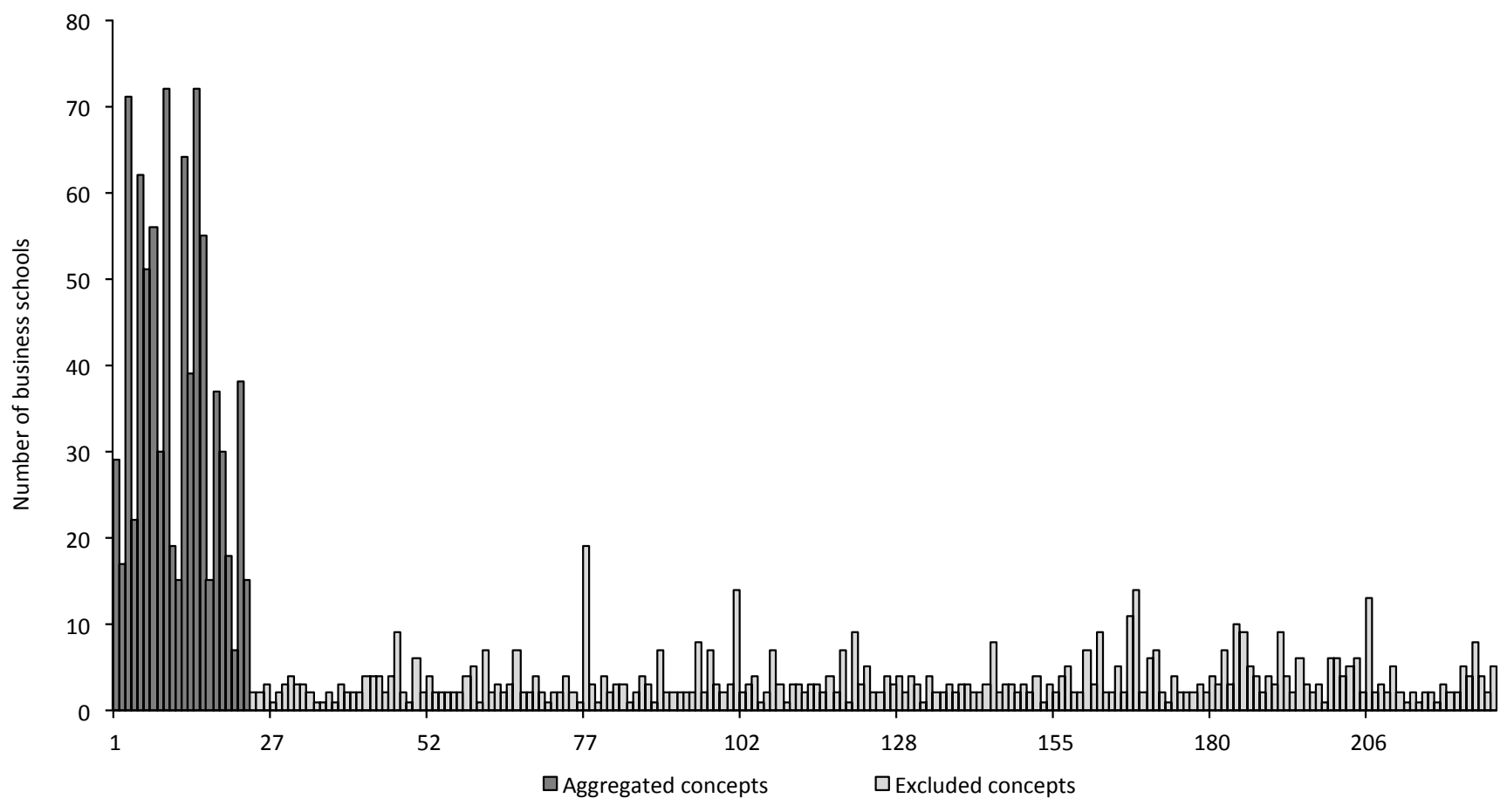

Figure 3: Distribution of aggregated excluded concept words across business schools

The results from the Marascuilo (1966) comparison of multiple proportions test are shown in Table 3. The first four columns of the table gives the number of mission statements within each quartile that contain the aggregated concepts. As illustration, aggregated concept "Management" occurs in fourteen, ten, four and nine of the twenty-five mission statements across the first through to fourth quartiles respectively. The fifth column of the table indicates that 0.37 or thirty-seven percent of the 100 mission statements contain the aggregated concept "Management". Columns six through eleven present the Marascuilo (1966) pairwise comparison of proportions tests for the six combinations of the four-quartile datasets. The 10.5042 value in the seventh column for "Management" is the Chi-square sample statistic for testing whether the first quartile proportion of 0.28 (fourteen out of twenty-five) is significantly different from the third quartile proportion of 0.08 (four out of twentyfive).

Examination of Table 3 shows that only two of the 132 (twenty-two times six) possible pairwise comparisons of proportion are significantly different at the $10 \%$ level of significance $^{6}$. Given that Type II statistical error could lead to the appearance of thirteen seemingly significant differences at the $10 \%$ test level when none actually exist, the conclusion is that the relative proportions of the twentytwo aggregated concepts across the quartiles are not different.

\footnotetext{
6 Aggregated concept "Management" shows a significant difference between the first and third quartile at the 5\% level, and for the aggregated concept "Enrollment" shows a significant difference between the second and third quartile at the $10 \%$ level.
} 
Table 3: Leximancer ${ }^{\mathrm{TM}}$ aggregated concept comparisons

\section{Q1 Q2 Q3 Q4 Prop.}

\begin{tabular}{|c|c|c|c|c|c|c|c|c|c|c|c|}
\hline & Q1 & Q2 & Q3 & Q4 & Prop. & $1 \& 2$ & $1 \& 3$ & $1 \& 4$ & $2 \& 3$ & $2 \& 4$ & $3 \& 4$ \\
\hline Aim & 9 & 6 & 6 & 8 & 0.29 & 0.8721 & 0.8721 & 0.0893 & 0.0000 & 0.4000 & 0.4000 \\
\hline Alumni & 4 & 1 & 5 & 7 & 0.17 & 2.0833 & 0.1359 & 1.0714 & 3.2258 & 6.0000 & 0.4425 \\
\hline Business & 17 & 19 & 18 & 17 & 0.71 & 0.4000 & 0.0954 & 0.0000 & 0.1042 & 0.4000 & 0.0954 \\
\hline Committed & 6 & 4 & 6 & 6 & 0.22 & 0.5051 & 0.0000 & 0.0000 & 0.5051 & 0.5051 & 0.0000 \\
\hline Create & 10 & 13 & 14 & 14 & 0.51 & 0.7353 & 1.3158 & 1.3158 & 0.0806 & 0.0806 & 0.0000 \\
\hline Develop & 16 & 17 & 13 & 10 & 0.56 & 0.0893 & 0.7500 & 3.0612 & 1.3699 & 4.2832 & 0.7353 \\
\hline Economic & 7 & 8 & 6 & 9 & 0.30 & 0.0954 & 0.1042 & 0.3704 & 0.4000 & 0.0893 & 0.8721 \\
\hline Education & 17 & 15 & 21 & 19 & 0.72 & 0.3497 & 1.8182 & 0.4000 & 3.8462 & 1.5152 & 0.5051 \\
\hline Environment & 4 & 1 & 8 & 6 & 0.19 & 2.0833 & 1.8182 & 0.5051 & $7.6563 *$ & 4.5290 & 0.4000 \\
\hline Ethical & 3 & 4 & 4 & 4 & 0.15 & 0.1667 & 0.1667 & 0.1667 & 0.0000 & 0.0000 & 0.0000 \\
\hline Excellence & 11 & 7 & 11 & 10 & 0.39 & 1.4286 & 0.0000 & 0.0822 & 1.4286 & 0.8152 & 0.0822 \\
\hline Global & 17 & 16 & 14 & 17 & 0.64 & 0.0893 & 0.7759 & 0.0000 & 0.3356 & 0.0893 & 0.7759 \\
\hline Leadership & 16 & 13 & 15 & 11 & 0.55 & 0.7500 & 0.0850 & 2.0973 & 0.3268 & 0.3226 & 1.3158 \\
\hline Management & 14 & 10 & 4 & 9 & 0.37 & 1.3158 & $10.5042 * *$ & 2.0973 & 3.8462 & 0.0850 & 2.7412 \\
\hline Provide & 8 & 6 & 6 & 10 & 0.30 & 0.4000 & 0.4000 & 0.3497 & 0.0000 & 1.5152 & 1.5152 \\
\hline Scholarship & 15 & 18 & 22 & 17 & 0.72 & 0.8152 & 5.6713 & 0.3497 & 2.0833 & 0.0954 & 3.0941 \\
\hline Service & 3 & 5 & 5 & 5 & 0.18 & 0.6024 & 0.6024 & 0.6024 & 0.0000 & 0.0000 & 0.0000 \\
\hline Society & 16 & 13 & 14 & 19 & 0.62 & 0.7500 & 0.3356 & 0.8721 & 0.0806 & 3.3333 & 2.3321 \\
\hline Staff & 1 & 2 & 1 & 3 & 0.07 & 0.3571 & 0.0000 & 1.1111 & 0.3571 & 0.2232 & 1.1111 \\
\hline Students & 7 & 11 & 6 & 14 & 0.38 & 1.4286 & 0.1042 & 4.3750 & 2.3321 & 0.7305 & 5.9701 \\
\hline Transformation & 2 & 6 & 5 & 2 & 0.15 & 2.5000 & 1.5411 & 0.0000 & 0.1168 & 2.5000 & 1.5411 \\
\hline Values & 4 & 5 & 1 & 5 & 0.15 & 0.1359 & 2.0833 & 0.1359 & 3.2258 & 0.0000 & 3.2258 \\
\hline
\end{tabular}

\begin{tabular}{|c|c|c|c|c|c|c|c|c|c|c|c|}
\hline & Q1 & Q2 & Q3 & Q4 & Prop. & $1 \& 2$ & $1 \& 3$ & $1 \& 4$ & $2 \& 3$ & $2 \& 4$ & $3 \& 4$ \\
\hline Aim & 9 & 6 & 6 & 8 & 0.29 & 0.8721 & 0.8721 & 0.0893 & 0.0000 & 0.4000 & 0.4000 \\
\hline Alumni & 4 & 1 & 5 & 7 & 0.17 & 2.0833 & 0.1359 & 1.0714 & 3.2258 & 6.0000 & 0.4425 \\
\hline Business & 17 & 19 & 18 & 17 & 0.71 & 0.4000 & 0.0954 & 0.0000 & 0.1042 & 0.4000 & 0.0954 \\
\hline Committed & 6 & 4 & 6 & 6 & 0.22 & 0.5051 & 0.0000 & 0.0000 & 0.5051 & 0.5051 & 0.0000 \\
\hline Create & 10 & 13 & 14 & 14 & 0.51 & 0.7353 & 1.3158 & 1.3158 & 0.0806 & 0.0806 & 0.0000 \\
\hline Develop & 16 & 17 & 13 & 10 & 0.56 & 0.0893 & 0.7500 & 3.0612 & 1.3699 & 4.2832 & 0.7353 \\
\hline Economic & 7 & 8 & 6 & 9 & 0.30 & 0.0954 & 0.1042 & 0.3704 & 0.4000 & 0.0893 & 0.8721 \\
\hline Education & 17 & 15 & 21 & 19 & 0.72 & 0.3497 & 1.8182 & 0.4000 & 3.8462 & 1.5152 & 0.5051 \\
\hline Environment & 4 & 1 & 8 & 6 & 0.19 & 2.0833 & 1.8182 & 0.5051 & $7.6563 *$ & 4.5290 & 0.4000 \\
\hline Ethical & 3 & 4 & 4 & 4 & 0.15 & 0.1667 & 0.1667 & 0.1667 & 0.0000 & 0.0000 & 0.0000 \\
\hline Excellence & 11 & 7 & 11 & 10 & 0.39 & 1.4286 & 0.0000 & 0.0822 & 1.4286 & 0.8152 & 0.0822 \\
\hline Global & 17 & 16 & 14 & 17 & 0.64 & 0.0893 & 0.7759 & 0.0000 & 0.3356 & 0.0893 & 0.7759 \\
\hline Leadership & 16 & 13 & 15 & 11 & 0.55 & 0.7500 & 0.0850 & 2.0973 & 0.3268 & 0.3226 & 1.3158 \\
\hline Management & 14 & 10 & 4 & 9 & 0.37 & 1.3158 & $10.5042 * *$ & 2.0973 & 3.8462 & 0.0850 & 2.7412 \\
\hline Provide & 8 & 6 & 6 & 10 & 0.30 & 0.4000 & 0.4000 & 0.3497 & 0.0000 & 1.5152 & 1.5152 \\
\hline Scholarship & 15 & 18 & 22 & 17 & 0.72 & 0.8152 & 5.6713 & 0.3497 & 2.0833 & 0.0954 & 3.0941 \\
\hline Service & 3 & 5 & 5 & 5 & 0.18 & 0.6024 & 0.6024 & 0.6024 & 0.0000 & 0.0000 & 0.0000 \\
\hline Society & 16 & 13 & 14 & 19 & 0.62 & 0.7500 & 0.3356 & 0.8721 & 0.0806 & 3.3333 & 2.3321 \\
\hline Staff & 1 & 2 & 1 & 3 & 0.07 & 0.3571 & 0.0000 & 1.1111 & 0.3571 & 0.2232 & 1.1111 \\
\hline Students & 7 & 11 & 6 & 14 & 0.38 & 1.4286 & 0.1042 & 4.3750 & 2.3321 & 0.7305 & 5.9701 \\
\hline Transformation & 2 & 6 & 5 & 2 & 0.15 & 2.5000 & 1.5411 & 0.0000 & 0.1168 & 2.5000 & 1.5411 \\
\hline Values & 4 & 5 & 1 & 5 & 0.15 & 0.1359 & 2.0833 & 0.1359 & 3.2258 & 0.0000 & 3.2258 \\
\hline
\end{tabular}

The first four columns count the number of mission statements that include the concept word; the fifth column contains the estimated proportion based on the whole sample; statistical significance for the Marscaiulo comparison of multiple proportions test (Marscaiulo, 1966) is based on Chi-square values with k-1 degrees of freedom; $\mathrm{k}$ is the number of proportions being tested for equivalence; critical Chi-square values for the various significance levels are at $10 \%$ : 6.2514 ; at 5\%: 7.8147; at 1\%: 11.345; these are flagged respectively as ***,***.

\section{Discussion}

\section{Implications for managers}

Research presented here demonstrates that the mission statements of business schools, at the group level at least, exhibit very few, if any, significant differences. There are no significant differences, for example, between the mission statements of business schools ranked in the top and fourth quartiles of the FT rankings. This implies that numerous schools in the sample do not have mission statements that permit them to be strongly positioned and highly differentiated, and suggests that the great majority are saying pretty much the same thing. Clearly, an individual school's mission statement would have to say some very distinctive things to stand out from the pack. This can be challenging because it may be difficult for schools to identify what makes them truly different. Schools that do differentiate themselves strongly in their mission statements, by not saying the same things most others, might define themselves out of the market. In a marketplace where good facilities and faculty, excellent research and teaching, and an espousal of high values are taken as given, finding the real differentiator, is hard indeed. Equally, the things that most schools espouse in their mission statements are important to most of the stakeholders, especially those who serve the school, and those it serves. The danger of not espousing these things is that such schools could end up talking about things that don't matter. Consequently, they could appear as less-than-legitimate. This is consistent with Ehrenberg,
Barnard, and Scriven (1997) who suggest that competitive brands seldom differ from one another as a defensive mechanism in order establish a presence in consumers' minds. They suggest that true differentiation occurs in execution - outperforming competitors in those areas that matter most.

So what is the leadership of a school to do? How can deans, with some responsibility for the mission statement and ensuing strategy, use these findings to better craft the school's mission statement and use it as a key device for driving strategy? Probably the best place to start is by comparing the school's current mission statement against the categories identified in this research (Table 3) and match what the statement espouses against them. Equally important, the dean can identify whether there is any strong and relevant terminology in the current mission statement that does not appear in any of the categories - terminology that could be a strong differentiator and allow the school to distance itself from the pack. A complete, or perfect, overlap might signal the need for the school to give serious thought to amending the mission statement to permit greater distinction and differentiation. Alternatively, deans at second and third-tier schools might choose to emulate a leading school's mission statement as a tacit comparison, essentially trading on the higher-ranked school's brand equity to reinforce its own - a tactic consumer brand managers know all too well. 
Another initiative that such a comparison might spark would be a return to the notion of defining the business rather than writing a mission statement. Criticisms of mission statements in the popular business press (for example, Chait, 1979), and in the academic literature (for example, Davies and Glaister, 1997; Bartkus et. al., 2000) have sprung from the fact that while many mission statements espouse high moral values, excellence and warmth in a myriad different ways $^{7}$, they don't tell you what the business does. Abell (1980) provides a simple, powerful, and useful framework. He suggests businesses needs to define themselves across three dimensions, and that this can essentially be done in one sentence. Three questions need to be answered. The "who" question - who are the customers we will serve? The "what" question - what customer needs will we satisfy? The "how" question - how will we satisfy those needs? In spite of the complexity that may exist for many universities that do not operate on a for-profit basis, Abell's (1980) notion of defining the business may be usefully interpreted in an educational context as defining the purpose - where purpose relates to the same "who", "what" and "how" questions articulated for the more corporate environment.

Business schools adopting this approach to defining their purpose, and perhaps going on to write their mission statement, may achieve significant advantages. They could produce a tool to test future decisions against that could drive strategy, regardless of whether this was communicated to stakeholders. For example, to examine ways of growing by finding new student populations, or to identify new needs, or to develop new ways of satisfying current needs. The single statement definition of purpose can also serve as the foundation for a subsequent mission statement that incorporates more issues, or caters to more stakeholders, or emphasizes values and priorities that the business school deems important, and that emphasizes the need for strategy to be re-thought on a regular basis. The definition of purpose will also need to be revisited as students and executive clients change, or their needs change, or the means of satisfying their needs changes.

Perhaps business schools need to consider that mission statements are not, ideally, carved in granite, but written in chalk on a blackboard.

\section{Limitations}

While we recognize that mission statements are clearly not the only tools that organizations use to position themselves in the marketplace, the four identified limitations to the study focus on the role of business school mission statements as professional communication tools.

1. Aside from being subject to the weaknesses inherent in the Financial Times ranking methodology, given that there are estimated to be over 13,000 business schools

\footnotetext{
${ }^{7}$ It is not for nothing that one of the most popular features on Scott Adams' well-known Dilbert cartoon website (www.dilbert.com) is an "instant mission statement generator" that generates ridiculous, but realisticsounding mission statements at random.
}

in the world, it might be argued that selecting an international business school ranking list constitutes selecting a relatively undifferentiated sample.

2. The data analysis of the mission statements in this research represents a snapshot in time and gives an indicative comparison of the mission statements of the hundred schools at the time we downloaded them.

3. The quartiles employed in the study use relative rankings to examine differences among mission statements of groups of business schools. Differences might have been more apparent had we used some other grouping such as country or region of origin that could have been impacted by culture.

4. Leximancer ${ }^{\mathrm{TM}}$ may have limitations that other computerized content analysis packages don't. In a sense, it imposes solutions on the textual data, where other content analysis packages such as WordStat ${ }^{\mathrm{TM}}$ (Peladeau, 1999) or DICTIONTM (Short \& Palmer, 2008) permit the researcher to introduce predetermined dimensions so that the resulting counts can be analyzed against these dimensions (columns) in a contingency table. The results can then be plotted using a procedure such as correspondence analysis that also facilitates a graphic map-like comparison (Greenacre, 1993).

\section{Avenues for future research}

A number of opportunities for future research emerge from this project. First, rather than using quartiles for comparison, alternative classifications can be considered. Categorization could be done on a geographic basis, by comparing standalone business schools against those attached to universities, or by comparing ranked business schools against those that do not form part of the rankings. Second, the analysis could be done on a longitudinal basis to see if shifts over time can be detected. Third, comparing business schools that achieve and lose their accreditation (AACSB International or EQUIS) or enter and exit a particular ranking may provide fruitful insight. Finally, and from a more managerial and user-centric perspective, developing a method for comparing the mission statement of an individual school against some predetermined sample could prove valuable. Individual schools could enter the text of their mission statements into a database, make comparisons against selected categories, and assess how well (or poorly) their mission statements distinguished them from the selected sample.

\section{Conclusion}

In this paper we have sought to answer the question of whether mission statements have allowed business schools to stand out or blend in, achieve distinction or homogeneity, and to position themselves. Our conclusion is that there is very little distinction and that the mission statements are broadly homogeneous. 
This begs the question: Is achieving distinction through a mission statement a "mission impossible" for a business school? Our evidence suggests distinction is extremely difficult because schools appear not to want to be ignored by not saying the right and expected things. Difficult, but probably not impossible! A few simple procedures might be used to craft a mission statement that drives strategy and to craft one that also enables differentiation through strong positioning. First, leadership should recognize that mission statements are not cast in stone, but fluid and dynamic instruments that should be continuously updated. Second, beginning with a definition of purpose, before proceeding to any mission statement, makes sense. This definition can then be extended and articulated into a mission statement that is different enough to be distinct. Individual schools can match their mission statements against the maps presented in this paper to determine where there is overlap, and where differences and similarities ought to be emphasized.

At best, mission statements can serve as clear communications to business schools' many stakeholders. At worst, they are benign, insignificant exercises in corporatespeak. Achieving mission distinction, either through deliberate homogeneity or clear heterogeneity, may be difficult - but it remains as possible, as it is desirable.

\section{References}

AACSB International. 2010. Eligibility procedures and accreditation standards for business accreditation. ( $2^{\text {nd }}$ rev.), http://www/aacsb.edu, accessed August 6, 2010.

Abell, D.F. 1980. Defining the business: The starting point of strategic planning, New York, NY: Prentice-Hall.

Amato, C.H. \& Amato, L.H. 2002. 'Corporate commitment to quality of life: Evidence from company mission statements', Journal of Marketing Theory and Practice, 10(4):69-87.

Baetz, M.C. \& Bart, C.K. 1996. 'Developing mission statements which work', Long Range Planning, 29(4):526-533.

Barber, M.P. 2005. The Money Tree and how to grow one: Creating success in your business. ( $2^{\text {nd }}$ ed.), www.Barberbooks.com, accessed August 6, 2010.

Bart, C.K. \& Baetz, M.C. 1998. 'The relationship between mission statements and firm performance: An exploratory study', Journal of Management Studies, 35(6):823-853.

Bartkus, B.R. \& Glassman, M. 2008. 'Do firms practice what they preach? The relationship between mission statements and stakeholder management', Journal of Business Ethics, 83: 207-216.

Bartkus, B., Glassman, M. \& McAfee, R.B. 2000. 'Mission statements: Are they smoke and mirrors?', Business Horizons, 43(3), 23-29.

Buff, C.L. \& Yonkers, V. 2004. 'How will they know right from wrong? A study of ethics in the mission statements and curriculum of AACSB undergraduate marketing programs', Marketing Education Review, 14(3), 71-79.
Campbell, C., Pitt, L., Parent, M. and Berthon, P. 2011. 'Understanding consumer conversations around ads in a Web 2.0 world', Journal of Advertising, 40(1), 87-102.

Chait, R. 1979. 'Mission madness strikes our colleges', Chronicle of Higher Education, 18:36.

David, F.R. 1989. 'How companies define their mission', Long Range Planning, 22(1), 90-97.

Davies, G.K. 1986. 'The importance of being general: Philosophy, politics and institutional mission statements', In J. C. Smart (ed.), Higher Education: Handbook of Theory and Research. New York: Agathon Press.

Davies, S.W. \& Glaister, K.W. 1997. 'Business school statements: The bland leading the bland', Long Range Planning, 30(4), 594 604.

Delucchi, M. 1997. "'Liberal arts" colleges and the myth of uniqueness', Journal of Higher Education, 68(4), 414-426.

Drucker, P. 1973. Management: Tasks, responsibilities, practices. New York: Harper \& Row.

Ehrenberg, A., Barnard, N. \& Scriven, J. 1997. 'Differentiation or salience', Journal of Advertising Research, 37 (Nov/Dec):6, 7-14.

European Foundation for Management Development. 2010. The EQUIS process manual: Annexes. www.efmd.org, accessed August 6, 2010.

Greenacre, M. 1993. Correspondence analysis in practice. Academic Press, New York, NY.

Hartley, M. 2002. A call to purpose: Mission-centered change at three liberal arts colleges. New York: RoutledgeFalmer.

Hemsley-Brown, J. \& Goonawardana, S. 2007. 'Brand harmonization in the international higher education market', Journal of Business Research, 60:942-948.

Hooley, G.J., Cox, A.J. \& Adams, A. 1992. 'Our five year mission - to boldly go where no man has been before', Journal of Marketing Management, 8:35-48.

Jones, M.H. 1960. 'Evolving a business philosophy', Journal of the Academy of Management, 3(2):93-98.

Keller, G. 1983. Academic strategy: The management revolution in American higher education. Baltimore: John Hopkins University Press.

Klemm, M., Sanderson, S. \& Luffman, G. 1991. 'Mission statements: Selling corporate values to employees', Long Range Planning, 24(3):73-78.

Koteen, J. 1997. Strategic management in public and nonprofit organizations: Managing public concerns in an era of limits, $\left(2^{\text {nd }}\right.$ ed.), Westport, CT: Praeger Publishers.

Krohe, J. 1995. 'Do you really need a mission statement?', Across the Board, 32:17-21.

Lee, M.Y., Fairhurst, A. \& Wesley, S. 2009. 'Corporate social responsibility: A review of the top 100 US retailers', Corporate Reputation Review, 12(2):140-158. 
Leland, D. \& Moore, J. 2007. 'Strategic focusing: Securing competitive advantage', Public Purpose, September/October:1013

Lowrie, A. 2007. 'Branding higher education: Equivalence and difference in developing identity', Journal of Business Research, 60:990-999.

Marascuilo, L.A. 1966. 'Large sample multiple comparisons', Psychological Bulletin, 65:280-290.

Martin, W.B. 1985. 'Mission: A statement of identity and direction', In Green, J. S. and Levine, A. (eds.), Opportunity in adversity. San Francisco: Jossey-Bass

Martin, N.J. \& Rice, J.L. 2007. 'Profiling enterprise risks in large computer companies using the Leximancer software tool', Risk Management, 9:188-206.

Meacham, J. 2008. 'What's the use of a mission statement?', Academe, 94(1):21 -24.

Meyer, N.D. 2005. Mission, vision and values statements. CIO Magazine. July $26 . \quad$ Available at http://www.cio.com/article/9311/IT_Mission_Vision_and_Values_ Statements, accessed January 3, $201 \overline{2}$.

Morphew, C.C. \& Hartley, M. 2006. 'Mission statements: A thematic analysis of rhetoric across institutional type', The Journal of Higher Education, 77(3):456-471.

Morphew C.C. \& Taylor B.J. 2009. College rankings and dueling mission statements. Chronicle of Higher Education, 19 August 2009, available at http://chronicle.com/ article/CollegeRankingsDueling $/ 48070 /$ ?sid $=$ at\&utm_source $=$ at\&utm_medium $=e$ n, accessed January 3, 2012.

Nanus, B. 1992. Visionary leadership: Creating a compelling sense of direction for your organization. San Francisco: Jossey-Bass.

Pearce II, J.A. \& David, F. 1987. 'Corporate mission statements: The bottom line', Academy of Management Executive, 1(2):109115 .

Pearce J. \& Robinson, R. 1991. Formulation, implementation and control of competitive strategy. Boston: Richard D. Irwin.

Peladeau, N. 1999. WordStat content analysis module for SIMSTAT - User's Guide. Montreal, Canada: Provalis Research.

Rooney, D. 2005. 'Knowledge, economy, technology and society: The politics of discourse', Telematics and Informatics, 22(4):405422.

Scott, N. \& Smith, A.E. 2005. 'Use of automated content analysis techniques for event image assessment', Tourism Recreation Research, 30(2):87-91.

Short, J. \& Palmer, T. 2008. 'Mission statements in U.S. colleges of business: An empirical examination of their content with linkages to configurations and performance', Academy of Management Learning and Education, 7(4):454-470.

Sidhu, J. 2003. 'Mission Statements: Is it time to shelve them?', European Management Journal, 21(4):439-446.
Smith, A.E., \& Humphreys, M.S. 2006. 'Evaluation of unsupervised semantic mapping of natural language with Leximancer concept mapping, Behaviour Research Methods, 38(2):262-279.

Verma, H.V. 2009. 'Mission statements - a study of intent and influence', Journal of Services Research, 9(2):153-172.

Wheelan, J. \& Hunger, J. 1989. Strategic Management and Business Policy. Singapore: Addison-Wesley. 